each side of us, which obviously, before our eyes, opened more and more, until as we left to resume our climb this new crevasse had widened to more than a couple of inches.

The chairman of the Association, Mr. Gerald Seligman, quoted recent work indicating that the individual crystal was the unit of glacier movement, and that the slightest differential movement of the crystal grains might well be one of the principal causes of glacier movement. It is to be hoped, and indeed expected, that confirmation or otherwise of this view, and the answer to Dr. Desch's question, may be forthcoming from the investigations now proceeding at the Jungfraujoch by Mr. Seligman and his collaborators.
In conclusion, it appears to me that practically every seriously suggested cause for the movement of glaciers that has ever been put forward does operate, each playing its part when the conditions are favourable to its operation, and several of them usually acting simultaneously. This opinion is not merely the result of an attempt to digest all the voluminous records of practical scientific work on glaciers, but of personal study commenced so long ago as the year 1891, materially assisted by careful examination of nearly two thousand photographs of ice and snow formations on glaciers and mountains, taken by me personally during more than thirty seasons spent in the Alps, besides visits to the Rocky Mountains and the Himalayas.

\title{
Cambridge Meeting of the British Association
}

\section{General Arrangements}

$\mathrm{T}$ HE Sectional programmes for the Cambridge meeting of the British Association were outlined in NATURE of July 16 ; it remains to add some general remarks to the notice which appeared in these columns when the preliminary programme was issued last April.

The attendance promises to be large : it should well exceed the average figure (which, since, but excluding, the centenary meeting in 1931, is 2,274 ); and this despite the umusually early, and to some members rather disconcerting, date of the meeting, August 17-24. This was inevitable, in order to meet the convenience of the colleges which are so generously offering their accommodation to visitors. Those who remember the last Cambridge meeting, in 1904, may recall that it fell on exactly the same dates, for the same reason. Nevertheless, the attendance then was 2,789 , a very high figure for those days, but one which the present officers (and especially the General Treasurer) would very gladly see surpassed this year. It may well be, however, that the indulgence of late-comers will have to be sought if there be not room for them all to hear Lord Rayleigh's presidential address on August 17. The same drawback supervened in 1904, when many were unavoidably excluded from the Corn Exchange in which Mr. Arthur (afterwards Lord) Balfour as president inaugurated the meeting. On the present occasion the address will be given in the Regal Cinema. There is more room there than in the Corn Exchange (and certainly those present will listen in conditions of greater comfort); but there may not be enough for all members. It has therefore been decided to number and reserve all seats and to issue tickets early next month to members according to priority of their intimation to be present ; any who receive tickets but who do not intend to use them will be besought to return them at once in order that they may be made available for other members. Consideration is being given to the desirability of relaying the address to another hall, a facility not available to the harassed officers in 1904 .

The general arrangements are nearing completion, and an ample list of excursions and visits has already been issued to those who have intimated intention to attend. The full programme and timetable, together with the specially compiled scientific survey of the Cambridge district, will be sent out as usual some ten days in advance of the meeting.

In recent years, the Association has attempted to meet a widespread demand for more specific attention to the direct relations between science and its bearing upon the life of the community, by the simple method of indicating in the programme all communications which bear specifically on this question. There will, however, be presented to the Council and the General Committee important proposals to place the study and presentation of this aspect of the advancement of science in a more clearly defined position within the Association. It will be recommended that a Division for the social and international relations of science be established-the Council having already approved this step in principle, and has appointed a committee to consider and report upon the method of working the new Division. The inclusion of international relations is made with the more confidence because the interest of the American 
Association for the Advancement of Science in these questions is well known, and a representative delegation from that body is expected at Cambridge to confer with the officers of the British Association upon the ways and means of closer co-operation. The report of the committee will be circulated early in August to all members of the General Committee known to intend to be present at the meeting. The same committee of the Council was charged with a review of the methods of publication at present practised by the Association, the principal medium being the annual report, which many people have long regarded as a graveyard of scientific communications the relegation of which thereto not infrequently appears to be something less than they deserve. A far-reaching proposal will be put forward in this connexion.

It will be apparent from previous announcements that the scientific programme will be full of worthy subjects, and one not previously mentioned calls for notice here. The visit of the scientific delegation to India last winter was so notable an episode that it has been felt to call for due recognition at Cambridge, and it is hoped to hold a special meeting, with Sir James Jeans, the jubilee president of the Indian Science Congress Association, in the chair, at which some of the delegates will give their impressions of the tour. Also an exhibition of photographs taken by delegates will be displayed in the reception room; the party was fortunate in including a number of very skilful amateur photographers. Another unaccustomed exhibition will be that of paintings and drawings by members of the Association, some of whom are already well known as artists in their hours of relaxation, though hitherto there has been too little opportunity to appreciate their work.

In certain directions, therefore, the Cambridge meeting may be expected to add materially to the history of the Association. In one other, it will assuredly do so. For the first time, a sherry party finds place in the official programme. It will be given in Emmanuel College by the Mayor and Mayoress of Cambridge-a very welcome innovation.

Among other social functions will be a reception by the University in the Senate House and Old Schools on Thursday evening, August 18. There will be informal conversaziones in Trinity College on Friday evening, August 19, and in St. John's College on Monday evening, August 22. Garden parties will be held in Downing College and Sidney Sussex College on Friday afternoon, August 19, and in Christ's College and Queens' College on Monday afternoon, August 22.

Full details of the social functions will be published in the programme and time-table.

\section{The Piltdown Man Discovery}

\section{Unveiling of a Monolith Memorial}

$\mathrm{O}^{\mathrm{N}}$ July 23, Sir Arthur Keith unveiled a monolith memorial which has been placed in the grounds of Barkham Manor, Piltdown, Sussex, to mark the spot where the late Mr. Charles Dawson found the fossil skull of Piltdown Man (Eoanthropus dawsoni). He paid a tribute to Mr. Dawson, whose important work as an amateur deserved our gratitude and remembrance. $\mathrm{He}$ remarked that the Piltdown skull is so different from any other human skull previously discovered, that the divergent opinions expressed by those who have attempted to interpret it are not surprising. In 1912-1913, when the fossil was found, much less was known of early man than is known at present. If a similarly novel discovery were made now, there would be closer agreement among those who studied it. Sir Arthur is more impressed at present with the simian characters of the skull and brain-cast, as well as those of the lower jaw, than he was when he originally examined the fossil.

After the unveiling, Sir Arthur Smith Woodward gave some reminiscences of his collaboration with Mr. Dawson at Piltdown, and he added that the first subscription towards the memorial was received from the late Prof. Henry Fairfield Osborn, of New York. Brigadier-General E. G. Godfrey-Faussett, chairman of Council of the Sussex Archæological Society, spoke of the generosity of landowners to archæologists, and expressed thanks to Mr. D. Kerr of Barkham Manor. The memorial was designed by Mr. Percival Bridgman of Lewes, and is made of durable Carboniferous sandstone from Yorkshire.

The following is the substance of Sir Arthur Keith's speech :

Mr. Charles Dawson-solicitor and antiquarianhas been in his grave these twenty-two years; he 